\title{
Metoclopramide Pretreatment for Prevention of Pain on Propofol Injection: A Randomized Placebo-Controlled Study
}

\author{
Muhammad Sazzad Hossain ${ }^{1}$, Syed Ariful Islam², Md. Afzalur Rahman³, \\ Md. Mahiuddin Alamgir ${ }^{4}$, Md. Waliullah ${ }^{5}$
}

\begin{abstract}
Background: Propofol, the most frequently used intravenous anaesthetic, is used for induction, maintenance of anaesthesia and for sedation in patients scheduled for routine elective surgical procedure. Pain on propofol injection still remains a considerable concern for the anaesthesiologist. Objective: Aim of this study was to observe the efficacy of metoclopramide as pretreatment for the prevention of pain caused by the propofol injection in patients undergoing elective surgery under general anaesthesia. Materials and method: A total of 80 patients were taken up in the study in the age group of 20 to 50 years of either sex, ASA grade I/II, scheduled for routine elective surgical procedure under general anesthesia with endotracheal intubation and using propofol as induction agent. The patients enrolled were divided randomly into two groups of 40 patients each. Group A received $10 \mathrm{mg}$ metoclopramide IV diluted in $5 \mathrm{ml}$ saline. Group $B$ received $5 \mathrm{ml}$ of normal saline as placebo before propofol injection. The patients were asked to report their pain according to the scale provided to them in the form of none, mild, moderate and severe after injection of propofol. Results: The overall incidence and severity of pain were significantly less in Group A (metoclopramide group) than in group B (placebo group) $(p<0.05)$. The incidence of mild and moderate pain in Group $A$ versus group $B$ was $15 \%$ vs $45 \%$ and $5 \%$ vs $25 \%$ respectively $(p<0.05)$. The incidence of score ' 0 ' (no pain) was higher in Group A (80\%) thanGroup B (25\%) ( $p<0.05)$. Conclusion: Intravenous metoclopramide is effective for relief of pain on propofol injection without any significant side effects.
\end{abstract}

Key words: Metoclopramide; pain on propofol injection (POPI).

Delta Med Col J. Jul 2019;7(2):71-75

\section{Introduction}

Propofol is one of the most widely used drugs for induction of anaesthesia, whose common application is due to high clearance and fast awakening of patient. ${ }^{1}$ Propofol induced anaesthesia is associated with adverse complications, including severe pain on injection, myoclonus, apnea, reduced blood pressure and rarely thrombophlebitis. The pain on propofol

1. Associate Professor and Head, Dept. of Anaesthesiology, National Institute of ENT (NIENT), Tejgaon, Dhaka, Bangladesh.

2. Medical officer, Dept. of Anaesthesiology. National Institute of ENT (NIENT), Tejgaon, Dhaka, Bangladesh.

3. Junior consultant, Dept. of Anaesthesiology, National Institute of ENT (NIENT), Tejgaon, Dhaka, Bangladesh.

4. Research officer, Dept. of Anaesthesiology, National Institute of ENT (NIENT), Tejgaon, Dhaka, Bangladesh.

5. Medical officer, Dept. of Anaesthesiology. National Institute of ENT (NIENT), Tejgaon, Dhaka, Bangladesh.

Correspondence: Muhammad Sazzad Hossain. e-mail: sazzadicu786@yahoo.com 
injection (POPI) is one of the major side effects and its incidence varies from $28 \%$ to $90 \%$ in adults. $^{2,3}$ The incidence of pain has been reported to be $80 \%$ to $90 \%$ in the case of injection in the back-of-hand vessels. ${ }^{4}$ Many patients reported severe pain after drug injection and some of them stated unbearable pain. 5 The patients suffering from injection induced pain may experience anxiety, fear and ischaemia or even myocardial infarction. ${ }^{6}$ Instead, reducing the injection-induced pain increases patient's satisfaction and safety. ${ }^{3}$ The pain on propofol injection (POPI) is attenuated through various techniques, including injection of drugs at different rates and fluid injection at intervals, change in the temperature of the injectable fluid, or combination with other drugs. ${ }^{4,7}$ One of the most accepted ways is pretreatment with lidocaine. ${ }^{7}$ However, studies have shown that this method does not relieve pain completely, and the patient's problem will continue. ${ }^{8}$ Other studies have suggested methods for controlling POPI, including the injection of low doses of narcotics such as sufentanil and butorphanol, $, 9,10$ injection in large vessels, lignocaine injection together with tourniquet closure, ${ }^{11}$ and cold-warm propofol. ${ }^{12}$ Some researchers used magnesium, ${ }^{13}$ beta blocker, ${ }^{14}$ 5-HT3 receptor antagonists, ${ }^{15}$ Alpha $^{2}$ agonists like dexmedetomidine ${ }^{3}$ and metoclopramide injection as a premedication for prevention of POPI.

Metoclopramide is a benzamide with both central and peripheral anti-emetic actions. In addition to this pharmacologic property, metoclopramide has local anaesthetic properties like those of lidocaine. ${ }^{16}$

The present prospective comparative study tried to evaluate the outcome of pretreatment by metoclopramide $10 \mathrm{mg}$ intravenously on pain on propofol injection (POPI) in comparison to placebo.

\section{Materials and method}

This was a randomized controlled double blind study conducted at National Institute of ENT (NIENT) Dhaka, Bangladesh, during March to May 2018. Eighty voluntarily consenting patients with American Society of Anesthesiologists (ASA) physical status class I and class II of either sex, aged 20-50 years who were scheduled to undergo elective surgical procedures that required general anesthesia with tracheal intubation were recruited into the study.

The exclusion criteria included patients with known cardiac disorders, other systemic disorders of lungs, kidney and liver, pregnant patients, patients for emergency procedures, those allergic to propofol and metoclopramide and patients with difficult airway.

Patients were randomly divided into two groups. The study drug was administered by an anaesthesiologist who was blinded to the constituents of the drug. Group A (metoclopramide group) received $10 \mathrm{mg}$ metoclopramide diluted in $5 \mathrm{ml}$ normal saline and Group B (placebo group) received $5 \mathrm{ml}$ normal saline.

Prior to surgery, the patients underwent thorough pre-anaesthetic check-up and required investigations. Patients were kept fasting for 8 hours. In the operation theatre, intravenous access was established with 20-gauge cannula in suitable vein on non-dominant hand and was infused with Ringer's lactate solution. Vital signs were measured by placing an electrocardiogram, a non-invasive blood pressure monitor, end tidal carbon-dioxide and a pulse oximeter on the patients. They were given $5 \mathrm{ml}$ of pre-treatment solution, containing either metoclopramide (group A) or $5 \mathrm{ml}$ normal saline (group B) intravenously after venous occlusion using blood pressure cuff around middle of the arm limiting inflation pressure to just above $50 \mathrm{mmHg}$ and locked in order to be sure that venous outflow was completely restricted. One minute later, the occlusion of venous drainage was released. This was followed by injection of $1 \%$ propofol, one-fourth of the calculated dose was injected over 15 seconds later the patient was assessed for pain during injection of propofolon a scale between 0-3 developed by McCrirrick and Hunter. ${ }^{17}$ The responses were evaluated as $0=$ no pain; 1 = mild pain (pain reported in response to questioning only, no behavioral signs); 
$2=$ moderate pain (pain reported in response to questioning and accompanied by behavioral signs); and 3 = severe pain (strong vocal response or response accompanied by facial grimacing, arm withdrawal or tears).

After pain assessment the remaining propofol was injected. After induction, patients were intubated and anaesthesia was maintained with nitrous oxide, oxygen halothane and vecuronium. At the end of surgery, residual neuromuscular blockade was antagonised with $0.05 \mathrm{mg} / \mathrm{kg}$ of neostigmine and $0.02 \mathrm{mg} / \mathrm{kg}$ of atropine. Extubation was done when the patients were fully awake and obeying commands.

For comparison of quantitative variables between the two groups, the unpaired t-test and for qualitative variables the Chi-squaretest was used. The statistical level of significance was $p<0.05$.

\section{Results}

There is no significant demographic difference between the groups (Table I). Basal mean arterial pressure (MAP) and heart rate are comparable in both groups. There is no significant difference of MAP and heart rate between metoclopramide and control groups during pre-intubation or three minutes post-intubation period $(p>0.05)$. (Table II)

The incidence of pain experienced in metoclopramide group (group A) is $20 \%$ and in group B (control group) is $75 \%$, which is statistically significant $\mathrm{p}<0.05$ (Table III). The severity of POPI is also lower in metoclopramide group than the control group $(\mathrm{p}<0.05)$ (Table III). The incidence of mild and moderate pain in Group A versus group B was $15 \%$ vs $45 \%$ and $5 \%$ vs $25 \%$ respectively, which were also statistically significant $(\mathrm{p}<0.05)$.

Table I: Comparison of demographic data between the two groups $(\mathrm{N}=80)$

\begin{tabular}{lccc}
\hline Parameters & Group A $(\mathbf{n}=\mathbf{4 0})$ & Group B $(\mathbf{n}=\mathbf{4 0})$ & p value \\
\hline $\begin{array}{l}\text { Age in years } \\
\text { (mean } \pm \text { SD) }\end{array}$ & $35.73 \pm 5.62$ & $36.43 \pm 6.32$ & $\mathrm{p}>0.05^{*}$ \\
$\begin{array}{l}\text { Weight in } \mathrm{kg} \\
\text { (mean } \pm \text { SD) }\end{array}$ & $66.52 \pm 7.26$ & $67.52 \pm 8.89$ & $\mathrm{p}>0.05^{*}$ \\
Sex (male/female) & $21 / 19$ & $22 / 18$ & $\mathrm{p}>0.05^{\#}$ \\
$\begin{array}{l}\text { ASA Physical status } \\
\text { I/II }\end{array}$ & $37 / 3$ & $36 / 4$ & $\mathrm{p}>0.05^{\#}$ \\
\hline
\end{tabular}

* Unpaired t test \& \# Chi-square test were done
Table II: Changes of mean arterial pressure and heart rate between two groups $(\mathrm{N}=\mathbf{8 0})$

\begin{tabular}{lccc}
\hline $\begin{array}{l}\text { Hemodynamic } \\
\text { parameter }\end{array}$ & $\begin{array}{c}\text { Basal } \\
\text { Group A/Group B }\end{array}$ & $\begin{array}{c}\text { Pre intubation } \\
\text { Group A/Group B }\end{array}$ & $\begin{array}{c}\text { Post intubation } \\
\text { Group A/Group B }\end{array}$ \\
\hline $\begin{array}{l}\text { Mean arterial pressure } \\
\text { (MAP) mm Hg }\end{array}$ & $105 / 107$ & $89 / 86$ & $108 / 110$ \\
Heart rate per minute & $82 / 85$ & $78 / 80$ & $95 / 97$ \\
\hline
\end{tabular}

Table III: Incidence pain following propofol injection between two groups $(\mathrm{N}=80)$

\begin{tabular}{|c|c|c|c|}
\hline Characteristics of pain & Group A $(n=40) \%$ & Group B $(n=40) \%$ & p value $^{\#}$ \\
\hline No pain & $32(80 \%)$ & $10(25 \%)$ & $\mathrm{p}<0.05$ \\
\hline Pain & $8(20 \%)$ & $30(75 \%)$ & $\mathrm{p}<0.05$ \\
\hline
\end{tabular}

\# Chi-square test was done

Table IV: Severity of pain following propofol injection between two groups $(\mathrm{N}=38)$

\begin{tabular}{lccc}
\hline Characteristics of pain & Group A (n=8) $\%$ & Group B $(\mathbf{n}=\mathbf{3 0}) \%$ & p value $^{\#}$ \\
\hline Mild Pain & $6(75 \%)$ & $18(60 \%)$ & $\mathrm{p}<0.05$ \\
Moderate pain & $2(25 \%)$ & $10(33.33 \%)$ & $\mathrm{p}<0.05$ \\
Severe pain & 0 & $2(6.66 \%)$ & $\mathrm{p}<0.05$
\end{tabular}

\# Chi-square test was done

\section{Discussion}

The present study compared the efficacy of metoclopramide to placebo as pretreatment agent in decreasing the incidence and severity of pain on propofol injection (POPI) in patients undergoing elective surgery under general anaesthesia. This study result shows the incidence of pain experienced in metoclopramide group is $20 \%$ and in control group is $75 \%(p<0.05)$. The severity of POPI is also lower in metoclopramide group than in the control group $(p<0.05)$. The incidence of mild and moderate pain in Group A versus group B was $15 \%$ vs $45 \%$ and $5 \%$ vs $25 \%$ respectively $(\mathrm{p}<0.05)$.

The pain alleviating effect of metoclopramide could be attributed to the facts that serotonin, (5-hydroxytryptamine [5-HT]), is a biological amine found in the brain and spinal cord and has a role in neurotransmission. ${ }^{18}$ Animal studies indicated that 5-HT3 antagonists reduce nociceptive responses of dorsal horn neurons when administered intrathecally by altering the 5-HT3 nociceptive receptors and this effect can be attributed to the antagonism to the stimulatory action of serotonin at 5-HT3 receptors that are 
involved in the nociceptive pathways. ${ }^{19}$ Also, Ye et $\mathrm{al}^{20}$ found 5-HT3 antagonists to be 15 times more effective than lignocaine as a local anaesthetic when injected under the skin in equal amounts. Moreover, 5-HT3 antagonists had been found to have sodium channel blocking action like lignocaine.

Tamer et $\mathrm{al}^{21}$ showed in their study that metoclopramide $10 \mathrm{mg}$ priming dose was as effective as lignocaine for prevention of propofol injection pain with an effect superior to 2.5 and 5 mg metoclopramide. These findings go in hand with Fujii \& Nakayama ${ }^{22}$ who found the combination of lignocaine with metoclopramide is more effective than lignocaine alone for reducing pain on injection of propofol in a peripheral vein. Fujii\& Shiga ${ }^{23}$ found metoclopramide is effective for reducing propofol injection pain, irrespective of patients' age but older people require and respond well to smaller doses. Fujii \& Nakayama $^{22}$ examined the effects of lignocaine administered with 3 different doses of metoclopramide or saline on pain of propofol injection in adults undergoing elective surgery and found that administration of lignocaine with metoclopramide in dose of 5 or $10 \mathrm{mg}$ was associated with lower incidence of pain.

Fujii \& Itakura ${ }^{24}$ compared the efficacy of lignocaine, metoclopramide, and flurbiprofenaxetil for reducing pain of propofol injection in adult surgical patients and reported an overall incidence of propofol-induced pain of $24 \%, 28 \%$ and $36 \%$, respectively, compared with placebo with non-significant difference of incidence and severity between the treated groups. Present study is nearly comparable to study done by Fiji \& Itakura ${ }^{24}$ where incidence of POPI by pretreatment with metoclopramide is $20 \%$ versus $28 \%$.

It can be concluded that, venous priming with a dose of $10 \mathrm{mg}$ metoclopramide administered with mid-arm tourniquet applied for one minute before propofol administration can reduce the incidence and severity of pain on propofol injection without significant adverse effects.

\section{References}

1. Majed MK, Emadi S, Nasiri E, Farzin D. Comparison of the Effects of Different Doses of Ketamine Propofol on Haemodynamic Changes of the Patients during Induction of Anesthesia. Journal of Mazandaran University of Medical Sciences. 2006;16(54):7-13.

2. Tan C, Onsiong M. Pain on Injection of Propofol. Anaesthesia. 1998;53(5):468-76.

3. He L, Xu JM, He T, Liu L, Zhu R. Dexmedetomidine Pretreatment Alleviates Propofol Injection Pain. Ups J Med Sci. 2014;119(4):338-42.

4. Kwak KH, Ha J, Kim Y, Jeon Y. Efficacy of Combination Intravenous Lidocaine and Dexamethasone on Propofol Injection Pain: A Randomized, Double-Blind, Prospective Study in Adult Korean Surgical Patients. Clin Ther. 2008;30(6):1113-19.

5. Jeon Y. Reduction of Pain on Injection of Propofol: Combination of Nitroglycerin and Lidocaine. J Anesth. 2012;26(5):728-31.

6. Morishima T, Sobue K, Arima H, Tanaka S, So M, Ando H, et al. Profound Pain Due to Propofol Injection Triggered Myocardial Ischemia in a Patient with a Suspected Pheochromocytoma. Anesth Analg. 2003;96(2):631.

7. Picard $P$, Tramèr MR. Prevention of Pain on Injection with Propofol: A Quantitative Systematic Review. Anesth Analg. 2000;90(4):963-69.

8. Yamakage M, Iwasaki S, Satoh JI, Namiki A. Changes in Concentrations of Free Propofol by Modification of the Solution. Anesth Analg. 2005;101(2):385-88.

9. Ghai B, Makkar JK, Bala I, Wig J. Effect of Parecoxib Pretreatment and Venous Occlusion on Propofol injection Pain: A Prospective, Randomized, Double-Blinded, Placebo-Controlled Study. J Clin Anesth. 2010;22(2):88-92.

10. Agarwal A, Raza M, Dhiraaj S, Pandey R, Gupta D, Pandey CK, et al. Pain during Injection of Propofol: The Effect of Prior Administration of Butorphanol. Anesth Analg. 2004; 99(1):117-19.

11. Kim DH, Chae YJ, Chang HS, Kim JA, Joe HB. Intravenous Lidocaine Pretreatment with Venous Occlusion for Reducing Microemulsion Propofol Induced Pain: Comparison of Three Doses of Lidocaine. J Int Med Res. 2014;42(2):368-75. 
12. Jeong M, Yoon H. Comparison of the Effects of Lidocaine Pre-Administration and Local Warming of the Intravenous Access Site on Propofol Injection Pain: Randomized, Double-Blind Controlled Trial. Int J Nurs Stud. 2016;61:209-18.

13. Sun J, Zhou R, Lin W, Zhou J, Wang W. Magnesium Sulfate Plus Lidocaine Reduces Propofol Injection Pain: A Double-blind, Randomized Study. Clin Ther. 2016;38(1):31-38.

14. Salman EA, Titiz L, Akpek E, Arslan G. Pretreatment with a Very Low Dose of Intravenous Esmolol Reduces Propofol Injection Pain. Agri. 2013;25(1):8-13.

15. Wang W, Zhou L, Wu LX, Wang T, Zhang CB, Sun L. 5-HT3 Receptor Antagonists for Propofol Injection Pain: A Meta-Analysis of Randomized Controlled Trials. Clin Drug Investig. 2016;36(4):243-53.

16. Fujii Y, Nakayama M. A Lidocaine/Metoclopramide Combination Decreases Pain on Injection of Propofol. Can J Anaesth. 2005;52(5):474-77.

17. McCrirrick A, Hunter S. Pain on Injection of Propofol: The Effect of Injectate Temperature. Anaesthesia. 1990;45:443-44.

18. Hindle AT. Recent Developments in the Physiology and Pharmacology of 5-Hydroxytryptamine. Br J Anaesth. 1994;73:795-807.
19. Ali Z, Wu G, Kozlov A, Barasi S. The Role of 5-HT3 in Nociceptive Processing in the Rat Spinal Cord: Results From Behavioral and Electrophysiological Studies. Neurosci Lett. 1996;208:203-207.

20. Ye JH, Mui WC, Hunt TE, Wu WH, Zbuzek VK. Ondansetron Exhibits the Properties of a Local Anesthetic. Anesth Analg. 1997;85:1116-21.

21. Tamer FS, Ahmed AM, Ahmed SR. Priming with Different Doses of Metoclopramide Preceded by Tourniquet Alleviates Propofol Induced Pain: A Comparative Study with Lidocaine. Egyptian J Anaesth. 2018;34:107-11.

22. Fujii Y, Nakayama M. Prevention of Pain Due to Injection of Propofol with IV Administration of Lidocaine $40 \mathrm{Mg}+$ Metoclopramide 2.5, 5, Or 10 Mg Or Saline: A Randomized, Double-Blind Study in Japanese Adult Surgical Patients. Clin Ther. 2007;29(5):856-61.

23. Fujii Y, Shiga Y. Age-Related Differences in Metoclopramide Requirement for Pain on Injection of Propofol. Clin Drug Invest. 2006;26(11):639-44.

24. Fujii Y, Itakura M. Comparison of Lidocaine, Metoclopramide, and Flurbiprofenaxetil for Reducing Pain on Injection of Propofol in Japanese Adult Surgical Patients: A Prospective, Randomized, Double-Blind, Parallel-Group, Placebo-Controlled Study. Clin Ther. 2008;30(2):280-86. 